\title{
Congenital Adrenal Hyperplasia: Classification of Studies Employing Psychological Endpoints
}

\author{
Stephanie A. Stout, Margarita Litvak, Natashia M. Robbins, and David E. Sandberg
}

Division of Child Behavioral Health, Department of Pediatrics \& Communicable Diseases, University of Michigan, 1500 E. Medical Center Drive, Ann Arbor, MI 48109-5318, USA

Correspondence should be addressed to David E. Sandberg, dsandber@med.umich.edu

Received 18 April 2010; Revised 7 July 2010; Accepted 30 July 2010

Academic Editor: John Fuqua

Copyright (๑) 2010 Stephanie A. Stout et al. This is an open access article distributed under the Creative Commons Attribution License, which permits unrestricted use, distribution, and reproduction in any medium, provided the original work is properly cited.

Psychological outcomes in persons with congenital adrenal hyperplasia (CAH) have received substantial attention. The objectives of this paper were to (1) catalog psychological endpoints assessed in CAH outcome studies and (2) classify the conceptual/theoretical model shaping the research design and interpretation of CAH-related psychological effects. A total of 98 original research studies, published between 1955 and 2009, were categorized based on psychological endpoints examined as well as the research design and conceptual model guiding analysis and interpretation of data. The majority of studies (68\%) investigated endpoints related to psychosexual differentiation. The preponderance of studies (76\%) examined a direct relationship (i.e., inferring causality) between prenatal androgen exposure and psychological outcomes. Findings are discussed in relation to the observed imbalance between theoretical interest in the role of prenatal androgens in shaping psychosexual differentiation and a broader conceptual model that examines the role of other potential factors in mediating or moderating the influence of CAH pathophysiology on psychological outcomes in both affected females and males. The latter approach offers to identify factors amenable to clinical intervention that enhance both health and quality of life outcomes in CAH as well as other disorders of sex development.

\section{Introduction}

Congenital adrenal hyperplasia $(\mathrm{CAH})$ comprises a family of autosomal recessive disorders involving impaired synthesis of cortisol. In 21-hydroxylase deficiency (21-OH CAH), the most common form comprising as many as $95 \%$ of new cases, excessive adrenal androgen biosynthesis results in masculinization of the genitals of $46, \mathrm{XX}$ offspring [1]. Similar to other chronic pediatric conditions, $\mathrm{CAH}$ has drawn the attention of clinical researchers interested in the psychological sequelae of the condition and factors contributing to variability in both physical health and quality of life outcomes of affected persons.

Hormone replacement in $\mathrm{CAH}$ is imperfect and does not mimic physiologic secretion. According to the 2002 Consensus Statement on 21-Hydroxylase Deficiency [2], the goal of treatment is the minimization of adrenal sex hormone and glucocorticoid excess, while simultaneously preventing premature or inappropriate virilization, optimizing growth and adult height, and preserving potential fertility. Because of the masculinizing effects of prenatal androgen excess on the genitalia, 21-OH CAH in 46, XX is now categorized as a disorder of sex development (DSD) [3]. According to the 2006 Consensus Statement on the Management of Intersex, DSD are "congenital conditions in which development of chromosomal, gonadal, or anatomic sex is atypical" [3] (p. e488). Both the CAH and DSD consensus statements recognize the stress on patient and family associated with a chronic life-threatening illness and, in the case of girls and women affected with $\mathrm{CAH}$, the added burden of atypical genital anatomy. The DSD consensus statement also notes that cultural and social factors modulate outcomes in affected persons and, therefore, recommends that these influences be taken into account in clinical care and research design. The statement charges clinicians and researchers to examine a wide range of psychological endpoints including 
"sexual function, and social and psychosexual adjustment, mental health, quality of life, and social participation" [3] (p. e493).

1.1. Psychological Endpoints in CAH. Much of what is known about the psychological development of persons affected with CAH (particularly females) stems from research focused on elucidating the influence of atypical sex hormone exposure during steroid-sensitive periods of brain development [4-6]. Prenatal androgen excess associated with masculinization of the genitalia is believed to influence the development of regions of the brain responsible for sex differences in behavior across a wide range of mammalian species, including humans [7-9]. Accordingly, CAH has been utilized as a model for testing hormonal hypotheses related to the influence of early androgen exposure on behaviors exhibiting sex-related variability, in particular psychosexual differentiation (i.e., gender identity, gender role, and sexual orientation) and sex differences in neurocognitive function.

Although the rate at which females with $\mathrm{CAH}$ experience gender dysphoria is significantly higher than in the general population, the large majority of females with CAH reared as girls develop a feminine gender identity and do not express feelings of gender dysphoria [10]. With regard to gender role (i.e., behaviors that differ in frequency or level between males and females that are promoted by social learning [11]), affected girls prefer toys and activities characterized as male typical $[12,13]$, are more likely to report the use of physical aggression in conflict situations [14], and are less interested in marriage, motherhood, and physical appearance [15] than unaffected girls. In the case of sexual orientation, affected women are more likely to have experienced homosexual fantasies or behavior than their unaffected relatives [16, 17]. Consistent with theories regarding the role of early androgens in the development of sex differences in cognitive function, girls with $\mathrm{CAH}$ exhibit enhanced spatial reasoning compared with unaffected siblings [18]. The apparent bias toward utilizing $\mathrm{CAH}$ as a model to test hormonal theories for the origins of sex differences in human behavior can be inferred from the relative scarcity of psychological outcome studies in CAH males. Affected males are of less interest in this regard because prenatal androgen levels in males are thought to fall within the normal range $[19,20]$ and because gendered behavior of boys with CAH appears typical [8].

In contrast to extensive research on gender-related phenomena, there has been relatively limited research addressing psychosocial adaptation in either females or males. These studies generally fail to show that $\mathrm{CAH}$ patients exhibit an increased incidence of psychopathology relative to the general population [21-23].

1.2. Conceptualization of the Effects of CAH on Psychological Outcomes. There are several ways to conceptualize the influence of $\mathrm{CAH}$ on psychological endpoints [24, 25]. The simple or direct effect model involves a single predictor (A) directly related to a single outcome (C). The potential influence of other variables is not considered in this model. An example of a direct effect model applied to behavioral outcomes would be a study comparing the sexual orientation of affected women to that of an unaffected female control group. An increased frequency of homosexuality or bisexuality has typically been attributed to the influence of prenatal androgen exposure on brain development $[16,17,26]$. Because other variables potentially impacting the endpoint of sexual orientation have not been formally examined or incorporated into the data-analytic strategy, prenatal androgen exposure, by default, becomes an appealing interpretation in light of animal experimental research [6-8]. However, this simplest of conceptual models does not reflect the view that sexual orientation in $\mathrm{CAH}$ women is likely multifactorially determined [27].

When the relationship between predictor and outcome is thought to be either buffered or intensified by another factor, then a more suitable model than one depicting a direct effect is one that tests for moderation. A moderator is a qualitative (e.g., sex, form of $\mathrm{CAH}$, salt wasting vs simple virilizing, family's ethnic background) or quantitative (e.g., age, serum testosterone levels) variable that influences the direction and/or strength of the relationship between predictor and outcome variables. In other words, moderation occurs when one variable affects the relationship between two other variables such that the impact of the predictor $(\mathrm{A})$ on the outcome (C) varies according to the level or value of the moderator (B). For example, gender assignment in 46, XX $\mathrm{CAH}$ appears to be moderated by the country in which the patient receives care. A comprehensive review of gender assignment decisions in Western industrialized countries shows that the vast majority of $46, \mathrm{XX}$ CAH patients have been reared as girls [10], while 46, XX CAH patients in more patriarchal societies (e.g., Turkey) have a higher rate of male gender assignment [28].

Finally, there are mediation models in which the mediator variable serves to clarify the nature of the relationship between the predictor and outcome [25]. Rather than hypothesizing a direct causal relationship between the predictor and outcome variables, a mediation model posits that the predictor (A) influences another variable (B) which, in turn, is more directly responsible for the outcome $(\mathrm{C})$. Potential examples of mediated effects of $\mathrm{CAH}$ on sexual behavior include studies examining the outcomes of genital surgery $[29,30]$. In these reports, reduced genital sensitivity and dissatisfaction or anxiety about genital appearance were identified as factors accounting for decreased sexual activity and pregnancy rates. The effect is not directly the consequence of having $\mathrm{CAH}$ but is mediated through experiences or consequences associated with its management.

Although incorporating a moderator or mediator in the conceptual model helps sharpen our understanding of the relationship between predictor and outcome, the researcher must secure a larger sample size to ensure adequate statistical power to demonstrate the influence of either [31, 32]. Because CAH is a relatively rare disease ( 1 in 15,000 births, only half of whom are $46, \mathrm{XX}$ ), problems arising from the larger sample size requirement may be remedied through multicenter studies.

The objective of the current paper is two-fold: first, to catalog studies of psychological endpoints assessed in 
CAH outcome studies and, second, to categorize these into domains and subdomains. This objective's importance flows from the consensus statement on DSD [3] which drew attention to the need to broaden the range of psychological outcomes investigated and attended to in clinical care. Second, it aims to classify the conceptual model (implicitly or explicitly) applied to account for $\mathrm{CAH}$-related effects on psychological endpoints.

\section{Materials and Methods}

2.1. Study Eligibility Criteria. Original research studies published in English between 1955 and 2009 were included in this paper if study participants included persons affected with 21-OH CAH (regardless of age or sex) and psychological variables (broadly defined) were measured. Literature reviews and research studies focusing on CAH pathophysiology that did not examine psychological endpoints were excluded. Similarly, studies were excluded if data from participants with varying medical diagnoses were combined such that results for participants with CAH could not be isolated.

Using the electronic databases OVID/Medline and PsycINFO, searches were performed by combining terms used to identify $\mathrm{CAH}$ with those likely to capture the broadest possible range of psychological endpoints (See Table 1). In OVID/Medline, the Medical Subject Heading (MeSH) "Adrenal Hyperplasia, Congenital," which encompasses "Adrenogenital Syndrome," was combined with the $\mathrm{MeSH}$ terms "Adjustment, Psychological" (capturing the terms behavior, adaptive; coping behavior; adaptation, psychologic; coping skills; psychological adaptation; psychological adjustment), "Stress, Psychological" (comprising anguish, emotional stress, life stress, mental suffering, and suffering), and the terms of psychosexual development; gender; gender identity; gender role; sexuality; sexual behavior; sexual dysfunction; sexual dysfunction, psychological; self-concept; body image; individual adjustment; quality of life; fertility; conception; personality inventory; career choice; religion; spirituality; psychopathology; mental disorders; cognition; interpersonal relations; marriage; social adjustment; social support; as well as results from the combinations of family + psychology, family + attitude, family + adjustment, and family + behavior. In the case of searches performed on the PsycINFO database, the terms "congenital adrenal hyperplasia," "adrenogenital syndrome," and "intersex" were paired with the psychosocial terms listed above. These procedures yielded a total of 98 articles.

2.2. Classification of Psychological Endpoints and Conceptual Model. Two raters (SS and ML) used study summary forms to reliably classify psychological endpoints assessed and research design used in each study. Psychological endpoints were classified into major domains and further divided into subdomains to achieve greater specificity (Table 1). Given that several studies examined multiple psychological endpoints, the tabled numbers exceed the total number of studies reviewed. Although most domain and subdomain labels are self-explanatory, the Psychological Factors subdomains warrant further explanation. Studies that employed standardized measures based on diagnostic criteria of the American Psychiatric Association Diagnostic and Statistical Manual [116] were categorized within the subdomain Psychopathology. Those studies examining behavioral and emotional symptoms, apart from diagnosable syndromes, were categorized as Behavioral/Emotional Functioning. With regard to the endpoint Health-Related Quality of Life, only those studies which utilized questionnaires designed specifically to assess this construct [117] were classified in this subdomain. Reproduction comprised two subdomains: studies which provided documentation of either the frequency of pregnancy or frequency with which CAHaffected women carried the pregnancy to term were classified under Conception; all other measured outcomes dealing with reproductive function were classified under Fertility Status. Studies examining psychological factors that could not reliably be classified within another domain/subdomain were listed as "Other." Examples of outcomes falling into this category included parental attitudes toward gender assignment $[33,34]$ or reactions to genital anomalies [28].

Reviewers also categorized studies based on their interpretation of the underlying conceptual model guiding study design and data analysis; that is, direct, mediated, or moderated. This aspect of the paper was complicated by the fact that investigators neither specified nor formally tested the fit of specific conceptual models according to accepted statistical practice (e.g., $[24,25,32]$ ) leaving it to the raters to infer the type of model guiding the research. Disagreements between raters were resolved by consensus involving the senior author (DES).

Finally, studies were also categorized as employing quantitative, qualitative, or mixed-methods (i.e., involving a combination of both quantitative and qualitative methodologies) [118] approaches. Quantitative research primarily uses a deductive process to test prespecified concepts, constructs, and hypotheses that make up a theory. The aim is to classify features, count them, and construct statistical models in an attempt to explain observed phenomena. In contrast, qualitative research primarily uses an inductive process to formulate theory. Qualitative research methods commonly involve detailed analysis of data such as transcripts from interviews. This approach is fundamentally more subjective, for example, by describing a problem or condition from the point of view of those experiencing it [119].

\section{Results}

3.1. Classification of Psychological Endpoints. Of the 98 articles reviewed, 67 (68\%) studied endpoints were classified in the Psychosexual Differentiation domain. The majority within this domain included an assessment of Gender Role ( $n=46,46 \%)$, followed by Gender Identity $(n=27,27 \%)$ and Sexual Orientation $(n=28,29 \%)$ (Table 1). The next most frequently investigated endpoints were categorized in the domain of Psychological Factors ( $n=28$ studies, 29\%). The remaining domains and subdomains are summarized 
TABLE 1: Classification of psychological endpoints by domain and subdomain ${ }^{\dagger}$.

\begin{tabular}{|c|c|c|}
\hline Domain (\# Studies) & Subdomain (\# Studies) & References \\
\hline \multirow{3}{*}{ Psychosexual Differentiation (67) } & Gender role (46) & \multirow{3}{*}[4,5,12-17,22,26,28,33-88]{} \\
\hline & Gender identity (27) & \\
\hline & Sexual orientation $(27)$ & \\
\hline \multirow{5}{*}{ Psychological Factors (30) } & Self-concept (18) & \multirow{5}{*}{$\begin{array}{l}{[5,21-23,28,30,33,40-} \\
42,49,51,55,57,65,69,71,72,74,81,86,87,89-96]\end{array}$} \\
\hline & Behavioral/emotional & \\
\hline & functioning (11) & \\
\hline & Psychopathology (10) & \\
\hline & Health-related quality of life (5) & \\
\hline \multirow{2}{*}{ Sexuality (25) } & Sexual function (2) & \multirow{2}{*}{$\begin{array}{l}{[16,26,29,30,38,40,41,43,50,52,65,69-72,81-} \\
84,87,89,97-100]\end{array}$} \\
\hline & Sexual activity $(17)$ & \\
\hline \multirow{2}{*}{ Social Adaptation (25) } & Social functioning (12) & \multirow{2}{*}{$\begin{array}{l}{[14,17,21,23,38,40,41,46,52,55,56,69-} \\
72,81,82,84,87,89,90,93,97,98,100]\end{array}$} \\
\hline & Cohabitation/marriage (15) & \\
\hline Cognitive Function (23) & & {$[4,28,35,48,53,55,57,64,67,98,101-113]$} \\
\hline \multirow{2}{*}{ Reproduction (10) } & Fertility status (7) & \multirow{2}{*}[40,50,52,70,85,87,89,94,114,115]{} \\
\hline & Conception (8) & \\
\hline Other $(8)$ & & {$[28,33,34,40,71,82,87,89]$} \\
\hline Education/Occupation (7) & & {$[51,65-67,87,92,100]$} \\
\hline
\end{tabular}

in Table 1. Studies employing quantitative methods alone comprised $76 \%$ of the reviewed literature, $18 \%$ were classified as qualitative, and $6 \%$ were applied to a combination of quantitative and qualitative strategies, that is, mixed methods (not shown in Table).

3.2. Classification of Conceptual Models. Seventy three of 98 studies (74\%) interpreted the psychological outcome as a direct consequence of CAH pathophysiology (Table 2). For example, masculinized gender-role behavior and neurocognitive profiles in affected girls are commonly explained in terms of a direct effect of excess prenatal androgen exposure on brain development in affected girls (e.g., $[35,36,101])$. The majority of studies within the domains of Psychosexual Differentiation (57 of 67), Psychological Factors (21of 30), Cognitive Function (22 of 23), Social Adaptation (19 of 25), Sexuality (13 of 25), Reproduction (8 of 10), and all studies examining Education/Occupation (7) endpoints applied a direct effect conceptual model.

A minority of reviewed studies (15 of 98, 15\%) examined the possibility that a third variable moderated the association between $\mathrm{CAH}$ and the outcome variable. Studies which adopted this approach targeted endpoints classified as Psychosexual Differentiation (8), Cognition (6), Sexuality (2), Psychological Factors (2), and Social Adaptation (2). For example, Berenbaum [37] demonstrated that effects of $\mathrm{CAH}$ on sex-typed play activities and interests were restricted to affected girls. The statistical interaction between sex of patient and type of play and interests constitutes evidence of a moderating variable. Across all studies, the moderator variable most frequently considered was participant's biological sex (13 of $15,87 \%)$ (Table 2).
A slightly higher proportion of studies (29 of 98, 30\%) adopted a mediation model (i.e., consideration that all or a portion of the influence of $\mathrm{CAH}$ on the outcome was mediated through another variable). Studies attending to the possibility of mediated effects tracked endpoints in the following domains: Psychosexual Differentiation (18), Sexuality (11), Psychological Factors (7), Social Adaptation (5), Other (4 articles examining family response to CAH and deepness of voice), Reproduction (3), and Cognition (1). For example, Zucker and colleagues [38] reported that for both women with $\mathrm{CAH}$ and their unaffected relatives, higher self-reported sexual arousability positively predicted relationship status, level of sexual attraction to men in fantasy, greater likelihood of heterosexual behavior, and more sexual experiences with men. The only statistically significant predictor of sexual arousability (for both CAH women and unaffected relatives) was lifetime sexual experiences with men. In other words, what differentiated $\mathrm{CAH}$ and healthy women was the amount of sexual experience by the time of study participation, whether or not they had CAH. Accordingly, if control group participants for any reason had more limited sexual experience, then they also would have been expected to show reduced sexual arousability. In this context, "sexual experience" is conceptualized as mediating the influence of CAH on sexual arousability.

Other examples of studies allowing for mediated effects included Hall et al. [39] and Slijper [88]; both introduced a control group comprised of comparably-aged patients with diabetes to control for "very similar life experiences that accompany their respective chronic illnesses: regular outpatient attendances, daily medication, decompensation during intercurrent illnesses, potentially life-threatening crises, and adverse impact on family life, schooling, and social life" [39]. 
TABLE 2: Summary of conceptual models applied to study of psychological endpoints ${ }^{\dagger}$.

\begin{tabular}{lcl}
\hline Conceptual Model & Number of Studies & References \\
\hline \multirow{2}{*}{ Direct Effect } & \multirow{2}{*}{$\begin{array}{l}{[4,5,12-17,21-23,26,28,35,36,38,40-42,44,46-48,50,51,53-} \\
\end{array}$} & $\begin{array}{l}56,58-61,64-70,72-80,83,84,86,87,89,90,92- \\
94,97,98,100,101,103-107,110-115]\end{array}$ \\
\hline \multirow{2}{*}{ Mediating } & 29 & $\begin{array}{l}{[16,30,33,34,38-40,43-45,49,50,52,56,57,62,63,71,74,80-} \\
82,85,88,91,95,96,99,102]\end{array}$ \\
\hline Moderating & 15 & {$[4,5,12,29,37,53,54,58,75,89,93,103,108,109,111]$} \\
\hline
\end{tabular}

${ }^{\dagger}$ Individual studies examined multiple endpoints; numbers of studies within domain/subdomain therefore exceed the total number of studies reviewed $(N=$ 98).

A total of 7 of 98 studies (7\%) incorporated a control group comprised of chronically ill participants.

\section{Discussion}

One objective of this paper was to catalog studies of $\mathrm{CAH}$ which included psychological endpoints. A total of 98 original studies published between 1955 and 2009 formed the dataset for our analysis. The majority of investigations ( $68 \%$ of total) examined endpoints related to psychosexual differentiation (i.e., gender identity, gender role, or sexual orientation). Classic $21-\mathrm{OH}$ in females has long served as a human model for the study of early androgen exposure effects on the developing brain. This focus accounts for the fact that affected males, assumed to be exposed to a relatively typical prenatal androgen milieu $[19,20]$, are underrepresented in $\mathrm{CAH}$ psychological outcome studies.

A number of potential problems emerge as a consequence of this arguably unbalanced research portfolio. For example, there is the risk that the emphasis on gender-role behavior in girls and women may be misinterpreted by consumers of this research (including healthcare providers, patients, and their families) as gender-atypical behavior being a significant source of concern rather than an observation primarily of theoretical importance [120]. Recent reports in the lay media [121-123], as well as an essay published on an authoritative bioethics website [120], suggest that this risk is, in fact, real. At the center of the current controversy is the practice of prescribing dexamethasone (dex) to pregnant women at risk for carrying a female fetus with CAH. Prenatal dex has been shown to diminish the degree of masculinization of female genitalia which may obviate the perceived need for genital surgery [124]. Research findings reported at a recent conference [125] suggest that this same treatment is associated with a similar reduction in the masculinization of behavior. The media and bioethicists interpreted interest in the gender outcome as indicating that the investigators believed that the gender behavior of these girls is a legitimate target for clinical intervention.

An overemphasis on gender-related outcomes has also been associated with a relative scarcity of studies investigating endpoints that relate more directly to improving clinical care. Previous work suggests that both the physical sequelae of the condition and modulation of circulating corticosteroids can affect psychological outcomes. For example, studies examining the influence of hirsutism, acne, short stature, or deep voice [87] on outcomes such as body image [40] provide information of potentially great relevance to clinical care, but such studies are relatively scarce. Furthermore, little attention is directed towards the effects of suboptimal hormone replacement therapy on emotional reactivity in male and female $\mathrm{CAH}$ patients. Studies have consistently found dysregulation of the hypothalamic-pituitary-adrenal (HPA) axis, particularly increases in corticotropin-releasing hormone $(\mathrm{CRH})$, to be related to symptoms of depression, anxiety, panic, and posttraumatic stress disorder [126]. Similarly, relatively little consideration has been given to the fact that adrenal medulla function is also compromised in 21$\mathrm{OH} \mathrm{CAH}$, resulting in decreased production of epinephrine. Plasma epinephrine and metanephrine concentrations are substantially lower in patients with CAH than in unaffected individuals, especially in those individuals who had been hospitalized for adrenal crisis [127]. Although apparently not life threatening, this deficiency may result in decreased endurance during long-term physical stress $[128,129]$. This aspect of adrenal function clearly warrants further study because of implications not only for the physical health of the $\mathrm{CAH}$-affected person but also for their health-related quality of life.

In addition to the restricted focus on endocrine abnormalities in CAH as predictors of outcomes, relatively little consideration has been given to social contextual factors (e.g., ethnic, religious, or familial environments [28]) in which intuition and a large body of evidence from the pediatric psychology literature $[130,131]$ suggest exerting strong and lasting effects on the development of children. In the case of $\mathrm{CAH}$, factors to consider include family adaptation to the birth and parenting of a child with a rare life-threatening chronic illness, decision-making regarding genital surgery in girls and its timing and possible decisional regret, to name only a few. Our review also revealed that relatively little attention has been directed toward constructs that may exert profound and lasting effects on the persons and their social relationships; examples include the development of a distorted body image and feelings of shame and fear of disclosure of medical information [30, 41, 42, 89]. This gap in theory-driven research makes it difficult to develop evidence-based psychosocial interventions to prevent or ameliorate predictable negative sequelae of $\mathrm{CAH}$ at different stages of development. Progress in this respect will be greatly facilitated through the development of health-related quality of life questionnaires that focus on issues specific to and 
shared by patients with CAH and other disorders of sex development and their families, which are not otherwise covered by generic health-related quality of life measures [132].

The second objective of this paper was to characterize the conceptual/theoretical models guiding individual studies. For many, the underlying conceptual model had to be inferred from the selection of control/comparison groups, the statistical analysis employed, or through the investigators' interpretation of the data. The majority of studies implicitly or explicitly posited a direct effect of prenatal CAH pathophysiology (i.e., elevated androgens) on the developing brain, and this tendency was most notable for studies examining gender-role behavior and cognitive function. However, even in the case of other psychosexual endpoints, where the evidence for organizational effects of prenatal androgens on the developing brain (i.e., gender identity and sexual orientation) has not been established, investigators rarely articulated (let alone statistically tested) for moderating or mediated effects. Instead, data analysis and interpretation suggested that the investigators assumed a causal rather than correlational relationship between $\mathrm{CAH}$ hormonal abnormalities and psychological outcomes.

The current paper also showed that the majority of studies $(76 \%)$ were quantitative, employing standardized measures to assess behavior in predetermined domains. Relatively few studies employed qualitative or mixed methods. Findings from several of these suggest the promise of this approach in identifying areas of particular relevance to clinical care. A poignant example comes from a qualitative study by May and colleagues [43]. It was reported that a lower percentage of women with CAH masturbated compared with women in a diabetes control group. Explanations given by $\mathrm{CAH}$ participants were illuminating. One participant described masturbation as a necessary medical procedure rather than one performed for sexual pleasure: " [masturbation was necessary] to keep it [the vagina] open. I have done so, everybody does, I used to have to, I would explore-what had [the surgeons] done? Even now, I've never thought about it for enjoyment" (p.484). Regardless of the generalizability of this observation, it suggests a direction for investigations examining the effects of medical examinations and procedures that may influence sexual experiences. In the same way, knowledge of patient subjective experiences such as these can directly inform the model of clinical care, for example, referral for sex therapy [3].

An implication of this paper is the need for larger sample sizes in order to test moderated and mediated models of $\mathrm{CAH}$ effects with adequate statistical power. Because $\mathrm{CAH}$ is a rare disease, the development of multisite collaborations is essential to progress. An example of such collaboration is Euro DSD, a consortium supported by the European Union [133]. As already noted, a broadened research agenda that includes assessment of psychological outcomes directly relevant to patients' lives will hopefully spur efforts in the development of well-informed psychosocial interventions.

Finally, two aspects of the methodology of this paper should be kept in mind: first, there is a possibility that some eligible studies were missed despite our best efforts to be complete. Because studies were identified using both Medline and PsychINFO databases, we do not believe that the addition of missed articles would fundamentally alter any of our findings or conclusions. Accuracy in categorization of studies according to the underlying conceptual model is more problematic. We made every effort to seek reliability in the process but expect that others, attempting the same task, might generate a somewhat different result than that summarized in Table 2. Here also, we do not expect that a reclassification of individual studies will fundamentally alter the conclusion that the majority of research on psychological endpoints in $\mathrm{CAH}$ arises from a direct effect model. Nonetheless, it should be noted that studies published in this special issue, but beyond the cutoff year for this paper (2009), hint at increased interest in the use of qualitative methods and examination of family contextual variables (e.g., $[134,135])$.

This paper will hopefully serve to encourage investigators to design new studies that attempt to model some degree of the complexity of the lives of children, adolescents, and adults (both women and men) with CAH and their families. Such approaches are firmly established in other areas of health research [136]. Because the theoretical framework for studying psychological outcomes of persons with DSD other than CAH is similarly focused on the putative action of androgens on sex-dimorphic brain development and psychosexual differentiation [137-139], it is perhaps obvious, but nonetheless worth mentioning, that all that has been stated in this paper regarding the $\mathrm{CAH}$ research agenda potentially applies to all other conditions currently categorized as DSD.

\section{Acknowledgments}

The project described was supported in part by Award no. R01HD053637 from the Eunice Kennedy Shriver National Institute of Child Health and Human Development. The content is solely the responsibility of the authors and does not necessarily represent the official views of the Eunice Kennedy Shriver National Institute of Child Health and Human Development or the National Institutes of Health. The authors thank Tom Mazur for encouraging them to prepare this paper as well as the research staff who assisted with its preparation, including Bijal Bhavsar, Kerrie Gillespie, and David Nguyen. Finally, they thank Melissa Gardner for comments on the paper.

\section{References}

[1] P. W. Speiser and P. C. White, "Congenital adrenal hyperplasia," New England Journal of Medicine, vol. 349, no. 8, pp. 776-788, 2003.

[2] Joint LWPES/ESPE CAH Working Group, "Consensus statement on 21-hydroxylase deficiency from the Lawson Wilkins Pediatric Endocrine Society and the European Society for Paediatric Endocrinology," Journal of Clinical Endocrinology and Metabolism, vol. 87, no. 9, pp. 4048-4053, 2002.

[3] P. A. Lee, C. P. Houk, S. F. Ahmed et al., "Consensus statement on management of intersex disorders," Pediatrics, vol. 118, no. 2, pp. e488-e500, 2006. 
[4] M. Hines, C. Brook, and G. S. Conway, "Androgen and psychosexual development: core gender identity, sexual orientation, and recalled childhood gender role behavior in women and men with congenital adrenal hyperplasia (CAH)," Journal of Sex Research, vol. 41, no. 1, pp. 75-81, 2004.

[5] S. A. Berenbaum, S. C. Duck, and K. Bryk, "Behavioral effects of prenatal versus postnatal androgen excess in children with 21-hydroxylase-deficient congenital adrenal hyperplasia," Journal of Clinical Endocrinology and Metabolism, vol. 85, no. 2, pp. 727-733, 2000.

[6] M. L. Collaer and M. Hines, "Human behavioral sex differences: a role for gonadal hormones during early development?" Psychological Bulletin, vol. 118, no. 1, pp. 55-107, 1995.

[7] B. S. McEwen and R. O. Greep, "Gonadal steroids influences on brain development and sexual differentiation," in Reproductive Physiology IV, International Review of Physiology, vol. 27, pp. 99-145, University Park Press, Baltimore, MD, USA, 1983.

[8] M. Hines, Brain Gender, Oxford University Press, New York, 2004.

[9] W. W. Beatty, "Gonadal hormones and sex differences in nonreproductive behaviors in rodents: organizational and activational influences," Hormones and Behavior, vol. 12, no. 2, pp. 112-163, 1979.

[10] A. B. Dessens, F. M. E. Slijper, and S. L. S. Drop, "Gender dysphoria and gender change in chromosomal females with congenital adrenal hyperplasia," Archives of Sexual Behavior, vol. 34, no. 4, pp. 389-397, 2005.

[11] S. Kassin, Psychology, Upper Saddle River, NJ, USA, Prentice Hall, 4th edition, 2003.

[12] S. A. Berenbaum and M. Hines, "Early androgens are related to childhood sex-typed toy preferences," Psychological Science, vol. 3, no. 3, pp. 203-206, 1992.

[13] S. A. Berenbaum and E. Snyder, "Early hormonal influences on childhood sex-typed activity and playmate preferences: implications for the development of sexual orientation," Developmental Psychology, vol. 31, no. 1, pp. 31-42, 1995.

[14] S. A. Berenbaum and S. M. Resnick, "Early androgen effects on aggression in children and adults with congenital adrenal hyperplasia," Psychoneuroendocrinology, vol. 22, no. 7, pp. 505-515, 1997.

[15] R. W. Dittmann, M. H. Kappes, M. E. Kappes et al., "Congenital adrenal hyperplasia II: gender-related behavior and attitutes in female salt-wasting and simple-virilizing patients," Psychoneuroendocrinology, vol. 15, no. 5-6, pp. 421434, 1990.

[16] R. W. Dittmann, M. E. Kappes, and M. H. Kappes, "Sexual behavior in adolescent and adult females with congenital adrenal hyperplasia," Psychoneuroendocrinology, vol. 17, no. 2-3, pp. 153-170, 1992.

[17] K. J. Zucker, S. J. Bradley, G. Oliver, J. Blake, S. Fleming, and J. Hood, "Psychosexual development of women with congenital adrenal hyperplasia," Hormones and Behavior, vol. 30, no. 4, pp. 300-318, 1996.

[18] E. Hampson, J. F. Rovet, and D. Altmann, "Spatial reasoning in children with congenital adrenal hyperplasia due to 21hydroxylase deficiency," Developmental Neuropsychology, vol. 14, no. 2-3, pp. 299-320, 1998.

[19] S. A. Wudy, H. G. Dörr, C. Solleder, M. Djalali, and J. Homoki, "Profiling steroid hormones in amniotic fluid of midpregnancy by routine stable isotope dilution/gas chromatography-mass spectrometry: reference values and concentrations in fetuses at risk for 21-hydroxylase deficiency," Journal of Clinical Endocrinology and Metabolism, vol. 84, no. 8, pp. 2724-2728, 1999.

[20] S. Pang, L. S. Levine, and L. L. Cederqvist, "Amniotic fluid concentrations of $\Delta 5$ and $\Delta 4$ steroids in fetuses with congenital adrenal hyperplasia due to 21-hydroxylase deficiency and in anencephalic fetuses," Journal of Clinical Endocrinology and Metabolism, vol. 51, no. 2, pp. 223-229, 1980.

[21] J. Helleday, G. Edman, E. M. Ritzen, and B. Siwers, "Personality characteristics and platelet MAO activity in women with congenital adrenal hypreplasia (CAH)," Psychoneuroendocrinology, vol. 18, no. 5-6, pp. 343-354, 1993.

[22] S. A. Berenbaum, K. K. Bryk, S. C. Duck, and S. M. Resnick, "Psychological adjustment in children and adults with congenital adrenal hyperplasia," Journal of Pediatrics, vol. 144, no. 6, pp. 741-746, 2004.

[23] A. H. Gordon, P. A. Lee, M. K. Dulcan, and D. N. Finegold, "Behavioral problems, social competency, and self perception among girls with congenital adrenal hyperplasia," Child Psychiatry and Human Development, vol. 17, no. 2, pp. 129138, 1986.

[24] G. N. Holmbeck, “Toward terminological, conceptual, and statistical clarity in the study of mediators and moderators: examples from the child-clinical and pediatric psychology literatures," Journal of Consulting and Clinical Psychology, vol. 65, no. 4, pp. 599-610, 1997.

[25] R. M. Baron and D. A. Kenny, "The moderator-mediator variable distinction in social psychological research. Conceptual, strategic, and statistical considerations," Journal of Personality and Social Psychology, vol. 51, no. 6, pp. 11731182, 1986.

[26] H. F. L. Meyer-Bahlburg, C. Dolezal, S. W. Baker, and M. I. New, "Sexual orientation in women with classical or non-classical congenital adrenal hyperplasia as a function of degree of prenatal androgen excess," Archives of Sexual Behavior, vol. 37, no. 1, pp. 85-99, 2008.

[27] H. F. L. Meyer-Bahlburg, "Psychobiologic research on homosexuality," Child and Adolescent Psychiatric Clinics of North America, vol. 2, pp. 489-500, 1993.

[28] H. Özbey, F. Darendeliler, H. Kayserili, Ü. Korkmazlar, and T. Salman, "Gender assignment in female congenital adrenal hyperplasia: a difficult experience," BJU International, vol. 94, no. 3, pp. 388-391, 2004.

[29] N. S. Crouch, L. M. Liao, C. R. Woodhouse, G. S. Conway, and S. M. Creighton, "Sexual function and genital sensitivity following feminizing genitoplasty for congenital adrenal hyperplasia," The Journal of Urology, vol. 179, no. 2, pp. 634638, 2008.

[30] S. Krege, K. H. Walz, B. P. Hauffa, I. Körner, and H. Rübben, "Long-term follow-up of female patients with congenital adrenal hyperplasia from 21-hydroxylase deficiency, with special emphasis on the results of vaginoplasty," BJU International, vol. 86, no. 3, pp. 253-258, 2000.

[31] G. H. McClelland and C. M. Judd, "Statistical difficulties of detecting interactions and moderator effects," Psychological Bulletin, vol. 114, no. 2, pp. 376-390, 1993.

[32] A. J. Fairchild and D. P. MacKinnon, "A general model for testing mediation and moderation effects," Prevention Science, vol. 10, no. 2, pp. 87-99, 2009.

[33] F. M. E. Slijper, S. L. S. Drop, J. C. Molenaar, and S. M. Muinck Keizer-Schrama, "Long-term psychological evaluation of intersex children," Archives of Sexual Behavior, vol. 27, no. 2, pp. 125-144, 1998. 
[34] V. Sripathi, S. Ahmed, N. Sakati, and A. Al-Ashwal, "Gender reversal in 46XX congenital virilizing adrenal hyperplasia," British Journal of Urology, vol. 79, no. 5, pp. 785-789, 1997.

[35] R. W. Dittmann, M. H. Kappes, and M. E. Kappes, "Cognitive functioning in female patients with 21-hydroxylase deficiency," European Child \& Adolescent Psychiatry, vol. 2, no. 1, pp. 34-43, 1993.

[36] B. Auyeung, S. Baron-Cohen, E. Ashwin et al., "Fetal testosterone predicts sexually differentiated childhood behavior in girls and in boys," Psychological Science, vol. 20, no. 2, pp. 144-148, 2009.

[37] S. A. Berenbaum, "Effects of early androgens on sex-typed activities and interests in adolescents with congenital adrenal hyperplasia," Hormones and Behavior, vol. 35, no. 1, pp. 102 110, 1999.

[38] K. J. Zucker, S. J. Bradley, G. Oliver, J. Blake, S. Fleming, and J. Hood, "Self-reported sexual arousability in women with congenital adrenal hyperplasia," Journal of Sex and Marital Therapy, vol. 30, no. 5, pp. 343-355, 2004.

[39] C. M. Hall, J. A. Jones, H. F. L. Meyer-Bahlburg et al., "Behavioral and physical masculinization are related to genotype in girls with congenital adrenal hyperplasia," Journal of Clinical Endocrinology and Metabolism, vol. 89, no. 1, pp. 419-424, 2004.

[40] L. Frisén, A. Nordenström, H. Falhammar et al., "Gender role behavior, sexuality, and psychosocial adaptation in women with congenital adrenal hyperplasia due to CYP21A2 deficiency," Journal of Clinical Endocrinology and Metabolism, vol. 94, no. 9, pp. 3432-3439, 2009.

[41] U. Kuhnle, M. Bullinger, H. P. Schwarz, and D. Knorr, "Partnership and sexuality in adult female patients with congenital adrenal hyperplasia. First results of a cross-sectional quality-of-life evaluation," Journal of Steroid Biochemistry and Molecular Biology, vol. 45, no. 1-3, pp. 123-126, 1993.

[42] L. Brinkmann, K. Schuetzmann, and H. Richter-Appelt, "Gender assignment and medical history of individuals with different forms of intersexuality: evaluation of medical records and the patients' perspective," Journal of Sexual Medicine, vol. 4, no. 4, pp. 964-980, 2007.

[43] B. May, M. Boyle, and D. Grant, "A comparative study of sexual experiences: women with diabetes and women with congenital adrenal hyperplasia due to 21-hydroxylase deficiency," Journal of Health Psychology, vol. 1, no. 4, pp. 479-492, 1996.

[44] S. A. Berenbaum and J. M. Bailey, "Effects on gender identity of prenatal androgens and genital appearance: evidence from girls with congenital adrenal hyperplasia," Journal of Clinical Endocrinology and Metabolism, vol. 88, no. 3, pp. 1102-1106, 2003.

[45] B. S. Bin-Abbas, N. A. Sakati, and A. A. Al-Ashwal, "Gender identity in congenital adrenal hyperplasia secondary to 11hydroxylase deficiency," Annals of Saudi Medicine, vol. 26, no. 3, pp. 239-241, 2006.

[46] R. W. Dittmann, M. H. Kappes, M. E. Kappes et al., "Congenital adrenal hyperplasia I: gender-related behavior and attitudes in female patients and sisters," Psychoneuroendocrinology, vol. 15, no. 5-6, pp. 401-420, 1990.

[47] R. W. Dittmann, "Body positions and movement patterns in female patients with congenital adrenal hyperplasia," Hormones and Behavior, vol. 26, no. 4, pp. 441-456, 1992.

[48] A. A. Ehrhardt, R. Epstein, and J. Money, "Fetal androgens and female gender identity in the early-treated adrenogenital syndrome," The Johns Hopkins Medical Journal, vol. 122, no. 3, pp. 160-167, 1968.
[49] S. R. Feldman, K. R. R. Krishnan, H. McPherson, and D. E. Meglin, "Organic affective disorder in a patient with congenital adrenal hyperplasia," Biological Psychiatry, vol. 22, no. 6, pp. 767-770, 1987.

[50] F. Gastaud, C. Bouvattier, L. Duranteau et al., "Impaired sexual and reproductive outcomes in women with classical forms of congenital adrenal hyperplasia," Journal of Clinical Endocrinology and Metabolism, vol. 92, no. 4, pp. 1391-1396, 2007.

[51] D. K. Gupta, S. Shilpa, A. C. Amini et al., "Congenital adrenal hyperplasia: long-term evaluation of feminizing genitoplasty and psychosocial aspects," Pediatric Surgery International, vol. 22, no. 11, pp. 905-909, 2006.

[52] L. J. Guth, R. I. Witchel, S. F. Witchel, and P. A. Lee, "Relationships, sexuality, gender identity, gender roles, and self-concept of individuals who have congenital adrenal hyperplasia: a qualitative investigation," Journal of Gay and Lesbian Mental Health, vol. 10, no. 2, pp. 57-75, 2006.

[53] M. Hines, B. A. Fane, V. L. Pasterski, G. A. Mathews, G. S. Conway, and C. Brook, "Spatial abilities following prenatal androgen abnormality: targeting and mental rotations performance in individuals with congenital adrenal hyperplasia," Psychoneuroendocrinology, vol. 28, no. 8, pp. 1010-1026, 2003.

[54] M. Hines and F. R. Kaufman, "Androgen and the development of human sex-typical behavior: rough-and-tumble play and sex of preferred playmates in children with congenital adrenal hyperplasia (CAH)," Child Development, vol. 65, no. 4, pp. 1042-1053, 1994.

[55] Z. Hochberg, M. Gardos, and A. Benderly, "Psychosexual outcome of assigned females and males with 46,XX virilizing congenital adrenal hyperplasia," European Journal of Pediatrics, vol. 146, no. 5, pp. 497-499, 1987.

[56] A. L. Hurtig and I. M. Rosenthal, "Psychological findings in early treated cases of female pseudohermaphroiditism caused by virilizing congenital adrenal hyperplasia," Archives of Sexual Behavior, vol. 16, no. 3, pp. 209-223, 1987.

[57] A. L. Hurtig, J. Radhakrishnan, H. M. Reyes, and I. M. Rosenthal, "Psychological evaluation of treated females with virilizing congenital adrenal hyperplasia," Journal of Pediatric Surgery, vol. 18, no. 6, pp. 887-893, 1983.

[58] M. Iijima, O. Arisaka, F. Minamoto, and Y. Arai, "Sex differences in children's free drawings: a study on girls with congenital adrenal hyperplasia," Hormones and Behavior, vol. 40, no. 2, pp. 99-104, 2001.

[59] J. C. Jorge, C. Echeverri, Y. Medina, and P. Acevedo, "Male gender identity in an XX individual with congenital adrenal hyperplasia," Journal of Sexual Medicine, vol. 5, no. 1, pp. 122-131, 2008.

[60] P. A. Lee and S. F. Witchel, “46,XX patients with congenital adrenal hyperplasia: initial assignment as male, reassigned female," Journal of Pediatric Endocrinology and Metabolism, vol. 18, no. 2, pp. 125-132, 2005.

[61] C. L. Leveroni and S. A. Berenbaum, "Early androgen effects on interest in infants: evidence from children with congenital adrenal hyperplasia," Developmental Neuropsychology, vol. 14, no. 2-3, pp. 321-340, 1998.

[62] A. Lev-Ran, "Gender role differentiation in hermaphrodites," Archives of Sexual Behavior, vol. 3, no. 5, pp. 391-424, 1974.

[63] D. N. Long, A. B. Wisniewski, and C. J. Migeon, "Gender role across development in adult women with congenital adrenal hyperplasia due to 21-hydroxylase deficiency," Journal of Pediatric Endocrinology and Metabolism, vol. 17, no. 10, pp. 1367-1373, 2004. 
[64] L. S. McGuire, K. O. Ryan, and G. S. Omenn, "Congenital adrenal hyperplasia. II. Cognitive and behavioral studies," Behavior Genetics, vol. 5, no. 2, pp. 175-188, 1975.

[65] H. F. L. Meyer-Bahlburg, R. S. Gruen, M. I. New et al., "Gender change from female to male in classical congenital adrenal hyperplasia," Hormones and Behavior, vol. 30, no. 4, pp. 319-332, 1996.

[66] H. F. L. Meyer-Bahlburg, C. Dolezal, S. W. Baker, A. A. Ehrhardt, and M. I. New, "Gender development in women with congenital adrenal hyperplasia as a function of disorder severity," Archives of Sexual Behavior, vol. 35, no. 6, pp. 667684, 2006.

[67] J. Money and V. G. Lewis, "Bisexually concordant, heterosexually and homosexually discordant: a matched-pair comparison of male and female adrenogenital syndrome," Psychiatry, vol. 50, no. 2, pp. 97-111, 1987.

[68] J. Money, M. Schwartz, and V. G. Lewis, "Adult erotosexual status and fetal hormonal masculinization and demasculinization: 46,XX congenital virilizing adrenal hyperplasia and 46,XY androgen-insensitivity syndrome compared," Psychoneuroendocrinology, vol. 9, no. 4, pp. 405-414, 1984.

[69] J. F. Morgan, H. Murphy, J. H. Lacey, and G. Conway, "Long term psychological outcome for women with congenital adrenal hyperplasia: cross sectional survey," British Medical Journal, vol. 330, no. 7487, pp. 340-341, 2005.

[70] R. M. Mulaikal, C. J. Migeon, and J. A. Rock, "Fertility rates in female patients with congenital adrenal hyperplasia due to 21-hydroxylase deficiency," New England Journal of Medicine, vol. 316, no. 4, pp. 178-182, 1987.

[71] L. E. Newman and R. J. Stoller, "Gender identity disturbances in intersexed patients," American Journal of Psychiatry, vol. 124, no. 9, pp. 1262-1266, 1968.

[72] A. Nordenskjöld, G. Holmdahl, L. Frisén et al., “Type of mutation and surgical procedure affect long-term quality of life for women with congenital adrenal hyperplasia," Journal of Clinical Endocrinology and Metabolism, vol. 93, no. 2, pp. 380-386, 2008.

[73] A. Nordenström, A. Servin, G. Bohlin, A. Larsson, and A. Wedell, "Sex-typed toy play behavior correlates with the degree of prenatal androgen exposure assessed by CYP21 genotype in girls with congenital adrenal hyperplasia," Journal of Clinical Endocrinology and Metabolism, vol. 87, no. 11, pp. 5119-5124, 2002.

[74] O. Oner, Z. Aycan, T. Tiryaki, D. Soy, E. Cetinkaya, and E. Kibar, "Variables related to behavioral and emotional problems and gender typed behaviors in female patients with congenital adrenal hyperplasia," Journal of Pediatric Endocrinology and Metabolism, vol. 22, no. 2, pp. 143-151, 2009.

[75] V. L. Pasterski, M. E. Geffner, C. Brain, P. Hindmarsh, C. Brook, and M. Hines, "Prenatal hormones and postnatal socialization by parents as determinants of male-typical toy play in girls with congenital adrenal hyperplasia," Child Development, vol. 76, no. 1, pp. 264-278, 2005.

[76] V. Pasterski, P. Hindmarsh, M. Geffner, C. Brook, C. Brain, and M. Hines, "Increased aggression and activity level in 3 - to 11-year-old girls with congenital adrenal hyperplasia (CAH)," Hormones and Behavior, vol. 52, no. 3, pp. 368-374, 2007.

[77] W. G. Reiner, "Gender identity and sex-of-rearing in children with disorders of sexual differentiation," Journal of Pediatric Endocrinology and Metabolism, vol. 18, no. 6, pp. 549-553, 2005.
[78] H. Richter-Appelt, C. Discher, and B. Gedrose, "Gender identity and recalled gender related childhood play-behaviour in adult individuals with different forms of intersexuality," Anthropologischer Anzeiger, vol. 63, no. 3, pp. 241-256, 2005.

[79] T. Sato and S. Koizumi, "Effects of fetal androgen on childhood behavior," Acta Paediatrica Japonica, vol. 33, no. 5, pp. 639-644, 1991.

[80] A. Servin, A. Nordenström, A. Larsson, and G. Bohlin, "Prenatal androgens and gender-typed behavior: a study of girls with mild and severe forms of congenital adrenal hyperplasia," Developmental Psychology, vol. 39, no. 3, pp. 440-450, 2003.

[81] N. M. M. L. Stikkelbroeck, C. C. M. Beerendonk, W. N. P. Willemsen et al., "The long term outcome of feminizing genital surgery for congenital adrenal hyperplasia: anatomical, functional and cosmetic outcomes, psychosexual development, and satisfaction in adult female patients," Journal of Pediatric and Adolescent Gynecology, vol. 16, no. 5, pp. 289-296, 2003.

[82] A. P. Van Seters and A. K. Slob, "Mutually gratifying heterosexual relationship with micropenis of husband," Journal of Sex and Marital Therapy, vol. 14, no. 2, pp. 98-107, 1988.

[83] A. B. Wisniewski, C. J. Migeon, M. A. Malouf, and J. P. Gearhart, "Psychosexual outcome in women affected by congenital adrenal hyperplasia due to 21-hydroxylase deficiency," Journal of Urology, vol. 171, no. 6, pp. 2497-2501, 2004.

[84] J. Woelfle, W. Hoepffner, W. G. Sippell et al., "Complete virilization in congenital adrenal hyperplasia: clinical course, medical management and disease-related complications," Clinical Endocrinology, vol. 56, no. 2, pp. 231-238, 2002.

[85] K. Hagenfeldt, P. O. Janson, G. Holmdahl et al., "Fertility and pregnancy outcome in women with congenital adrenal hyperplasia due to 21-hydroxylase deficiency," Human Reproduction, vol. 23, no. 7, pp. 1607-1613, 2008.

[86] H. F. L. Meyer-Bahlburg, C. Dolezal, S. W. Baker, A. D. Carlson, J. S. Obeid, and M. I. New, "Prenatal androgenization affects gender-related behavior but not gender identity in 5-12-year-old girls with congenital adrenal hyperplasia," Archives of Sexual Behavior, vol. 33, no. 2, pp. 97-104, 2004.

[87] U. Kuhnle and M. Bullinger, "Outcome of congenital adrenal hyperplasia,” Pediatric Surgery International, vol. 12, no. 7, pp. 511-515, 1997.

[88] F. M. Slijper, "Androgens and gender role behaviour in girls with congenital adrenal hyperplasia (CAH)," Progress in Brain Research, vol. 61, pp. 417-422, 1984.

[89] M. Langer, W. Grunberger, and M. Ringler, "Vaginal agenesis and congenital adrenal hyperplasia. Psychosocial sequelae of diagnosis and neovagina formation," Acta Obstetricia et Gynecologica Scandinavica, vol. 69, no. 4, pp. 343-349, 1990.

[90] T. H. Johannsen, C. P. L. Ripa, E. L. Mortensen, and K. M. Main, "Quality of life in 70 women with disorders of sex development," European Journal of Endocrinology, vol. 155, no. 6, pp. 877-885, 2006.

[91] M. Brand, E. Schoof, C.-J. Partsch et al., "Anorexia nervosa in congenital adrenal hyperplasia: long-term follow-up of 4 cases," Experimental and Clinical Endocrinology and Diabetes, vol. 108, no. 6, pp. 430-435, 2000.

[92] J. Jääskeläinen and R. Voutilainen, "Long-term outcome of classical 21-hydroxylase deficiency: diagnosis, complications and quality of life," Acta Paediatrica, vol. 89, no. 2, pp. 183187, 2000.

[93] R. Knickmeyer, S. Baron-Cohen, B. A. Fane et al., "Androgens and autistic traits: a study of individuals with congenital 
adrenal hyperplasia," Hormones and Behavior, vol. 50, no. 1, pp. 148-153, 2006.

[94] U. Kuhnle, M. Bullinger, and H. P. Schwarz, "The quality of life in adult female patients with congenital adrenal hyperplasia: a comprehensive study of the impact of genital malformations and chronic disease on female patients life," European Journal of Pediatrics, vol. 154, no. 9, pp. 708-716, 1995.

[95] C. Ning, L. Green-Golan, C. A. Stratakis et al., "Body image in adolescents with disorders of steroidogenesis," Journal of Pediatric Endocrinology and Metabolism, vol. 21, no. 8, pp. 771-780, 2008.

[96] U. Nygren, M. Södersten, H. Falhammar, M. Thorén, K. Hagenfeldt, and A. Nordenskjöld, "Voice characteristics in women with congenital adrenal hyperplasia due to 21hydroxylase deficiency," Clinical Endocrinology, vol. 70, no. 1, pp. 18-25, 2009.

[97] A. A. Ehrhardt, K. Evers, and J. Money, "Influence of androgen and some aspects of sexually dimorphic behavior in women with the late-treated adrenogenital syndrome," The Johns Hopkins Medical Journal, vol. 123, no. 3, pp. 115-122, 1968.

[98] J. Money, "Psychologic approach to psychosexual misidentity with elective mutism: sex reassignment in two cases of hyperadrenocortical hermaphroditism," Clinical Pediatrics, vol. 7, no. 6, pp. 331-339, 1968.

[99] N. S. Crouch, C. L. Minto, L.-M. Laio, C. R.J. Woodhouse, and S. M. Creighton, "Genital sensation after feminizing genitoplasty for congenital adrenal hyperplasia: a pilot study," BJU International, vol. 93, no. 1, pp. 135-138, 2004.

[100] A. Lev-Ran, "Sexuality and educational levels of women with the late-treated adrenogenital syndrome," Archives of Sexual Behavior, vol. 3, no. 1, pp. 27-32, 1974.

[101] G. A. Mathews, B. A. Fane, V. L. Pasterski, G. S. Conway, C. Brook, and M. Hines, "Androgenic influences on neural asymmetry: handedness and language lateralization in individuals with congenital adrenal hyperplasia," Psychoneuroendocrinology, vol. 29, no. 6, pp. 810-822, 2004.

[102] S. M. Resnick, S. A. Berenbaum, I. I. Gottesman, and T. J. Bouchard Jr., "Early hormonal influences on cognitive functioning in congenital adrenal hyperplasia," Developmental Psychology, vol. 22, no. 2, pp. 191-198, 1986.

[103] S. C. Mueller, V. Temple, E. Oh et al., "Early androgen exposure modulates spatial cognition in congenital adrenal hyperplasia (CAH)," Psychoneuroendocrinology, vol. 33, no. 7, pp. 973-980, 2008.

[104] E. Plante, C. Boliek, A. Binkiewicz, and W. K. Erly, "Elevated androgen, brain development and language/learning disabilities in children with congenital adrenal hyperplasia," Developmental Medicine and Child Neurology, vol. 38, no. 5, pp. 423-437, 1996.

[105] E. Sinforianil, C. Livieri, M. Mauri et al., "Cognitive and neuroradiological findings in congenital adrenal hyperplasia," Psychoneuroendocrinology, vol. 19, no. 1, pp. 55-64, 1994.

[106] T. H. Johannsen, C. P. L. Ripa, J. M. Reinisch, M. Schwartz, E. L. Mortensen, and K. M. Main, "Impaired cognitive function in women with congenital adrenal hyperplasia," Journal of Clinical Endocrinology and Metabolism, vol. 91, no. 4, pp. 1376-1381, 2006.

[107] M. D. C. Donaldson, P. H. Thomas, J. G. Love, G. D. Murray, A. W. McNinch, and D. C. L. Savage, "Presentation, acute illness, and learning difficulties in salt wasting 21-hydroxylase deficiency," Archives of Disease in Childhood, vol. 70, no. 3, pp. 214-218, 1994.
[108] W. M. Kelso, M. E. R. Nicholls, G. L. Warne, and M. Zacharin, "Cerebral lateralization and cognitive functioning in patients with congenital adrenal hyperplasia," Neuropsychology, vol. 14, no. 3, pp. 370-378, 2000.

[109] W. M. Kelso, M. E. R. Nicholls, and G. L. Warne, "Effects of prenatal androgen exposure on cerebral lateralization in patients with congenital adrenal hyperplasia (CAH)," Brain and Cognition, vol. 40, no. 1, pp. 153-156, 1999.

[110] V. G. Lewis, J. Money, and R. Epstein, "Concordance of verbal and nonverbal ability in the adrenogenital syndrome," The Johns Hopkins Medical Journal, vol. 122, no. 4, pp. 192-195, 1968.

[111] F. S. Maheu, D. P. Merke, E. A. Schroth et al., "Steroid abnormalities and the developing brain: declarative memory for emotionally arousing and neutral material in children with congenital adrenal hyperplasia," Psychoneuroendocrinology, vol. 33, no. 2, pp. 238-245, 2008.

[112] M. A. Malouf, C. J. Migeon, K. A. Carson, L. Petrucci, and A. B. Wisniewski, "Cognitive outcome in adult women affected by congenital adrenal hyperplasia due to 21-hydroxylase deficiency," Hormone Research, vol. 65, no. 3, pp. 142-150, 2006.

[113] L. S. McGuire and G. S. Omenn, "Congenital adrenal hyperplasia. I. Family studies of IQ," Behavior Genetics, vol. 5, no. 2, pp. 165-173, 1975.

[114] A. Casteràs, P. De Silva, G. Rumsby, and G. S. Conway, "Reassessing fecundity in women with classical congenital adrenal hyperplasia $(\mathrm{CAH})$ : normal pregnancy rate but reduced fertility rate," Clinical Endocrinology, vol. 70, no. 6, pp. 833-837, 2009.

[115] N. Krone, I. Wachter, M. Stefanidou, A. A. Roscher, and H. P. Schwarz, "Mothers with congenital adrenal hyperplasia and their children: outcome of pregnancy, birth and childhood," Clinical Endocrinology, vol. 55, no. 4, pp. 523-529, 2001.

[116] American Psychiatric Association, Diagnostic and Statistical Manual of Mental Disorders: DSM-IV-TR, American Psychiatric Association, Washington, DC, USA, 2000.

[117] E. F. Juniper, G. H. Guyatt, R. Jaeschke, and B. Spilker, "How to develop and validate a new health-related quality of life instrument," in Quality of Life and Pharmacoeconomics in Clinical Trials, vol. 2, pp. 49-56, Lippincott-Raven Publishers, Philadelphia, PA, USA, 1996.

[118] J.W. Creswell, V. L. Plano Clark, M. Gutman, W. Hanson, A. Tashakkori, and C. Teddlie, "Advanced mixed methods research designs," in Handbook on Mixed Methods in the Behavioral and Social Sciences, Sage, Thousand Oaks, CA, USA, 2003.

[119] J. W. Creswell, Qualitative Inquiry \& Research Design, Sage, Thousand Oaks, CA, USA, 2007.

[120] A. Dreger, E. Feder, and A. Tamar-Mattis, "Preventing homosexuality (and uppity women) in the womb?" Bioethics Forum, 2010, http://www.thehastingscenter.org/ Bioethicsforum $/$ Post.aspx?id=4754\&blogid=140\&terms $=$ uppity+and+\%23filename+*.html.

[121] S. Begley, "The anti-lesbian drug," Newsweek, 2010, http:// www.newsweek.com/2010/07/02/the-antilesbian-drug.print .html.

[122] C. Elton, "A prenatal treatment raises questions of medical ethics," Time Magazine, 2010, http://www.time.com/ time/printout/0,8816,1996453,00.html.

[123] A. Coghlan, "Debate over gender disorder drug," New Scientist, 2010, http://www.newscientist.com/article/dn19151International Journal of Pediatric Endocrinology 11debateover-gender-disorder-drug.html?. 
[124] S. Nimkarn and M. I. New, "Congenital adrenal hyperplasia due to 21-hydroxylase deficiency: a paradigm for prenatal diagnosis and treatment," Annals of the New York Academy of Sciences, vol. 1192, pp. 5-11, 2010.

[125] M. New, "Long range outcome of prenatal treatment," in Proceedings of the 2nd World Conference, Hormonal and Genetic Basis of Sexual Differentiation Disorders and Hot Topics in Endocrinology, Miami, FL, USA, 2010.

[126] M. Ising and F. Holsboer, "CRH1 receptor antagonists for the treatment of depression and anxiety," Experimental and Clinical Psychopharmacology, vol. 15, no. 6, pp. 519-528, 2007.

[127] D. P. Merke, G. P. Chrousos, G. Eisenhofer et al., "Adrenomedullary dysplasia and hypofunction in patients with classic 21-hydroxylase deficiency," New England Journal of Medicine, vol. 343, no. 19, pp. 1362-1368, 2000.

[128] M. Weise, B. Drinkard, S. L. Mehlinger et al., "Stress dose of hydrocortisone is not beneficial in patients with classic congenital adrenal hyperplasia undergoing short-term, highintensity exercise," Journal of Clinical Endocrinology and Metabolism, vol. 89, no. 8, pp. 3679-3684, 2004.

[129] L. Green-Golan, C. Yates, B. Drinkard et al., "Patients with classic congenital adrenal hyperplasia have decreased epinephrine reserve and defective glycemic control during prolonged moderate-intensity exercise," Journal of Clinical Endocrinology and Metabolism, vol. 92, no. 8, pp. 3019-3024, 2007.

[130] A. E. Kazak, M. T. Rourke, T. A. Crump, and M. C. Roberts, "Families and other systems in pediatric psychology," in Handbook of Pediatric Psychology, vol. 3, pp. 159-175, Guildford Press, New York, NY, USA, 2003.

[131] A. L. Quittner, M. A. Davis, A. C. Modi, and M. C. Roberts, "Health-related quality of life in pediatric populations," in Handbook of Pediatric Psychology, pp. 696-709, Guilford Press, New York, NY, USA, 2003.

[132] D. Sandberg, M. Gardner, B. Kogan et al., "Developing a measure of health-related quality of life in disorders of sex development: phase I-item generation," in Proceedings of the 2nd World Conference, Hormonal and Genetic Basis of Sexual Differentiation Disorders and Hot Topics in Endocrinology, Miami, FL, 2010.

[133] Euro DSD, 2010, http://www.eurodsd.eu/index.php.

[134] M. A. Malouf, A. G. Inman, A. G. Carr, J. Franco, and L. M. Brooks, "Health-related quality of life, mental health and psychotherapeutic considerations for women diagnosed with a disorder of sexual development: congenital adrenal hyperplasia," International Journal of Pediatric Endocrinology, vol. 2010, Article ID 253465, 11 pages, 2010.

[135] D. A. Fedele, K. Kirk, C. Wolfe-Christensen et al., "Primary caregivers of children affected by disorders of sex development: mental health and caregiver characteristics in the context of genital ambiguity and genitoplasty ," International Journal of Pediatric Endocrinology, vol. 2010, Article ID 690674, 7 pages, 2010.

[136] T. Wills and S. Cleary, "Testing theoretical models and frameworks in child health research," in Pediatric and Clinical Child Psychology: Practical Strategies and Methods, D. Drotar, Ed., pp. 21-49, Kluwer Academic / Plenum Publishers, New York, NY, USA, 2000.

[137] P. T. Cohen-Kettenis, "Gender change in 46,XY persons with $5 \alpha$-reductase- 2 deficiency and $17 \beta$-hydroxysteroid dehydrogenase-3 deficiency," Archives of Sexual Behavior, vol. 34, no. 4, pp. 399-410, 2005.
[138] T. Mazur, "Gender dysphoria and gender change in androgen insensitivity or micropenis," Archives of Sexual Behavior, vol. 34, no. 4, pp. 411-421, 2005.

[139] H. F. L. Meyer-Bahlburg, "Gender identity outcome in female-raised 46,XY persons with penile agenesis, cloacal exstrophy of the bladder, or penile ablation," Archives of Sexual Behavior, vol. 34, no. 4, pp. 423-438, 2005. 